\title{
Anti-inflammatory components of the Vietnamese starfish Protoreaster nodosus
}

\author{
Nguyen Phuong Thao ${ }^{1,2}$, Bui Thi Thuy Luyen ${ }^{1,2}$, Jung Eun Koo ${ }^{3}$, Sohyun $\mathrm{Kim}^{3}$, Young Sang Koh ${ }^{3}$, \\ Nguyen Xuan Cuong ${ }^{1}$, Nguyen Hoai Nam ${ }^{1}$, Phan Van Kiem ${ }^{1}$, Young Ho Kim ${ }^{2^{*}}$ and Chau Van Minh ${ }^{1 *}$
}

\begin{abstract}
Background: In the present study, we examined the inhibitory effects of a methanolic extract, dichloromethane fraction, water layer, and polyhydroxylated sterols (1-4) isolated from the Vietnamese starfish Protoreaster nodosus on pro-inflammatory cytokine (IL-12 p40, IL-6, and TNF-a) production in LPS-stimulated bone marrow-derived dendritic cells (BMDCs) using enzyme-linked immunosorbent assays (ELISA).

Results: The methanolic extract and dichloromethane fraction exerted potent inhibitory effects on the production of all three pro-inflammatory cytokines, with $I C_{50}$ values ranging from $0.60 \pm 0.01$ to $26.19 \pm 0.64 \mu \mathrm{g} / \mathrm{mL}$. Four highly pure steroid derivatives (1-4) were isolated from the dichloromethane fraction and water layer of $P$. nodosus. Potent

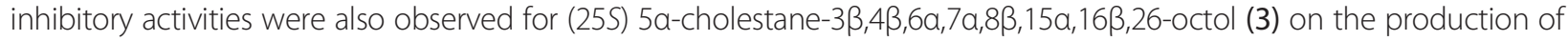

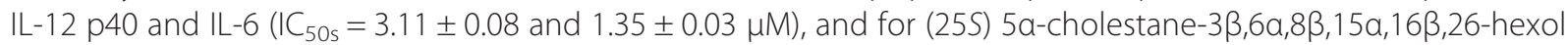

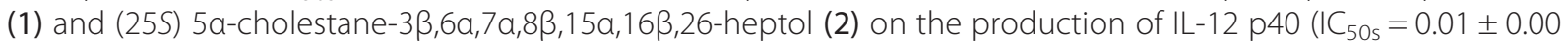
and $1.02 \pm 0.01 \mu \mathrm{M}$ ). Moreover, nodososide (4) exhibited moderate inhibitory effects on IL-12 p40 and IL-6 production.

Conclusion: This is the first report of the anti-inflammatory activity from the starfish $P$. nodosus. The main finding of this study is the identification oxygenated steroid derivatives from $P$. nodosus with potent anti-inflammatory activities that may be developed as therapeutic agents for inflammatory diseases.
\end{abstract}

Keywords: Protoreaster nodosus, Starfish, IL-12 p40, IL-6, TNF-a, LPS-stimulated BMDCs, Anti-inflammatory

\section{Background}

Inflammation is one of the earliest innate immune responses to tissue injury and various pathological stimuli. It is also a critical early factor in wound healing. Delayed or impaired inflammation may affect the later stages of wound healing, especially granulation formation [1,2]. Inflammation, which represents part of the complex biological response of vascular tissue to harmful exogenous harmful stimuli, is mediated by a variety of soluble factors, including a group of secreted polypeptides known as cytokines, which play key roles in the modulation of immune responses [3].

Interleukin (IL)-12 is a pro-inflammatory cytokine produced by activated antigen-presenting cells, dendritic cells,

\footnotetext{
*Correspondence: yhk@cnu.ac.kr; cvminh@vast.vn

${ }^{2}$ College of Pharmacy, Chungnam National University, Daejeon 305-764, Republic of Korea

'Institute of Marine Biochemistry (IMBC), Vietnam Academy of Science and

Technology (VAST), 18 Hoang Quoc Viet, Caugiay, Hanoi, Vietnam

Full list of author information is available at the end of the article
}

monocytes/macrophages, and $\mathrm{B}$ cells in response to bacterial products and immune signals [4]. Originally identified as a B-cell differentiation factor, IL- 6 is now known to be a multifunctional cytokine that participates in several biological events, including immune responses, hematopoiesis, and acute-phase reactions [5]. The regulatory effects of IL-6 involve the inhibition of tumor necrosis factor (TNF) production, providing negative feedback, and limiting acute inflammatory responses [6,7]. Cytokines such as IL-6 are essential, but their constitutive overproduction is involved in various diseases. This account for the negative regulatory mechanism in the IL- 6 signaling system $[8,9]$.

TNF has since been implicated in diverse inflammatory, infectious, and malignant conditions, and the importance of TNF in inflammation was demonstrated by the efficacy of anti-TNF antibodies or the administration of soluble TNF receptors (TNFRs) in controlling rheumatoid arthritis and other inflammatory conditions $[10,11]$. TNF is not typically detectable in healthy individuals, but serum 
and tissue levels are elevated under of inflammatory and infection [12]. Additionally, serum TNF levels correlate with the severity of infections [11]. Therefore, inhibiting the expression and production of powerful mediators, including IL-12 p40, IL-6, and TNF- $\alpha$, using antiinflammatory components could represent a preventive or therapeutic target, and may be used to develop anti-inflammatory agents for health promotion and disease prevention.

Starfish are found in all oceans. There are more than 1,500 known species, and many remain undiscovered. Forcipulatida, Paxillosida, Platyasterida, Spinulosida, and Valvatida are the main subclasses of Asteroidea. Starfish have been investigated by organic chemists, biochemists, and pharmacologists as a potential source of bioactive marine natural products. Various secondary metabolites, including steroids, steroidal glycosides, anthraquinones, alkaloids, phospholipids, peptides, and fatty acids, have been reported in starfish [13]. Steroids and their glycosylated derivatives with unique structures are known to possess anti-tumor, anti-inflammatory [14], immunomodulatory, anti-allergy, anti-fungal, hemolytic [15], neuritogenic [16], antinociceptive [17], cytotoxic [18-20], and anti-viral [21] activities.
The starfish Protoreaster nodosus (Linnaeus, 1758) is an invertebrate belong to the order Phanerozonia, class Asteroidea, and phylum Echinodermata. Members of the genus Protoreaster are found in the warm Vietnamese sea, and have been historically used as tonic agents in Vietnamese folk medicine. However, studies on the biological activities of $P$. nodosus are limited. In previous studies, the main constituents of $P$. nodosus were found to be polyhydroxylated steroids [22], several of which exhibited moderate cytotoxicity, steroidal glycoside sulfates [23], galactocerebrosides [24], and gangliosides [25].

As part of our ongoing investigations of Vietnamese marine organisms regarding anti-inflammatory activity [26-31], we found that a methanolic extract and dichloromethane fraction of $P$. nodosus showed significant in vitro anti-inflammatory effects. The present study details the inhibitory effect of steroid derivatives (1-4, Figure 1) from the starfish $P$. nodosus on the LPS-induced expression of the pro-inflammatory cytokines IL-12 p40, IL-6, and TNF- $\alpha$ in BMDCs.

\section{Results and discussion}

Natural marine products have recently become the focus of increased research interest due to their potential

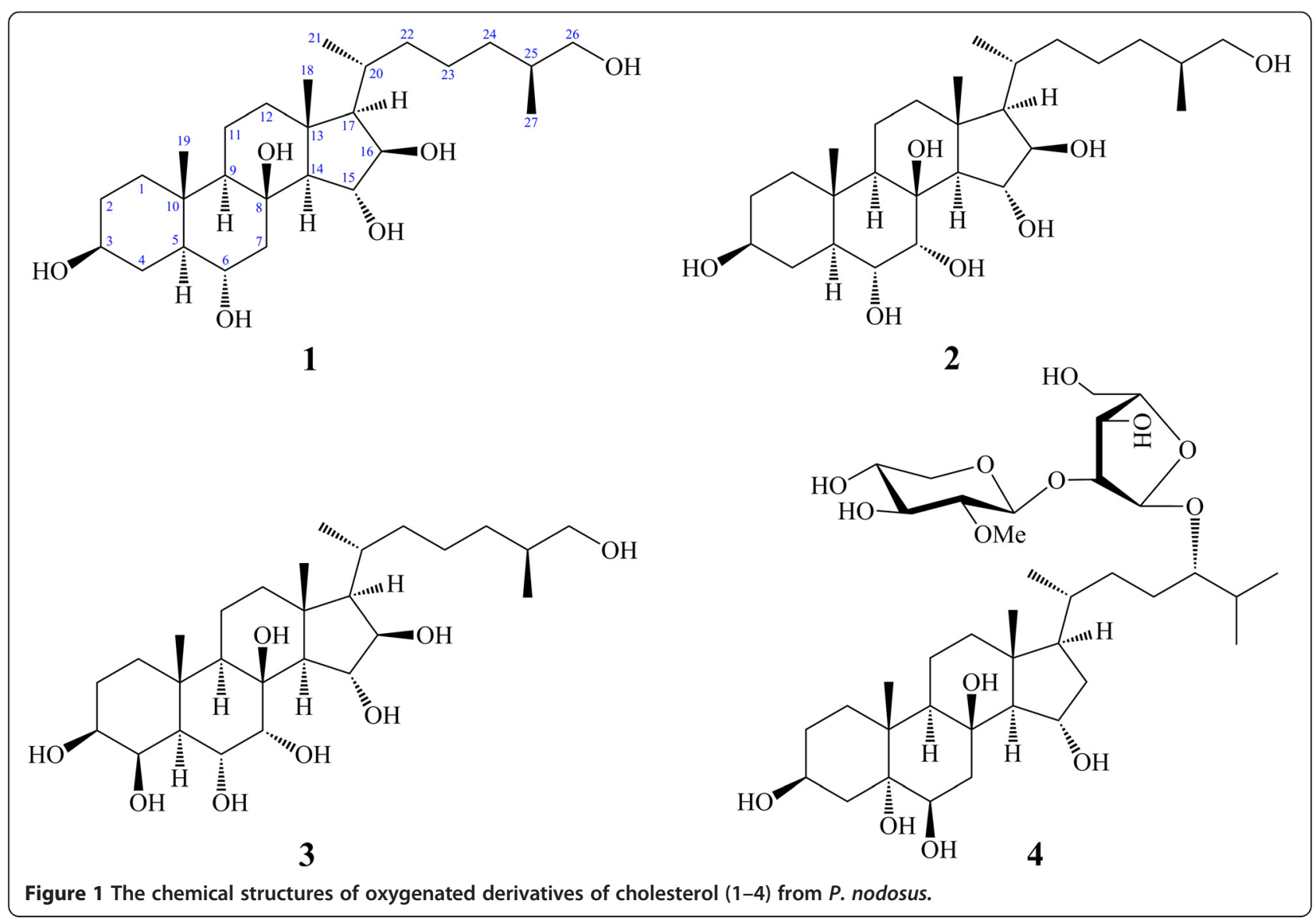


pharmacological activities and low-level toxicity [32,33]. Oxysterols, or oxygenated derivatives of cholesterol produced through autooxidation or in vivo enzymatic processes, and have been identified in mammalian tissues and cells (e.g., blood) and processed foods. Oxysterols are emerged as intriguing substances with diverse biological activities $[34,35]$. Recently, it was shown that oxysterolinduced cell death shares many common features with apoptotic cell death [19], which plays an important role in the balance between cell proliferation and cell death. A wide range of stimuli can trigger cell death, which is an irreversible process $[20,36]$.

BMDCs play a key role in the interface between the innate and acquired immune systems. Activated BMDCs perform crucial functions in immune and inflammatory responses via the pathogen-associated molecular patterns (PAMPs)-stimulated production of pro-inflammatory cytokines such as IL-12 p40, IL-6, and TNF- $\alpha$, which are involved in the pathogenesis of cardiovascular and neurodegenerational diseases and cancers through a series of cytokine signaling pathways. It has been demonstrated that pro-inflammation is associated with pathophysiology and is connected with various clinical disease manifestations. These pro-inflammatory cytokines play a crucial role in host defenses and inflammation $[37,38]$.

Among its many biological activities, IL-12 provides an obligatory signal for the differentiation of effector T-helper type 1 (Th1) cells and the secretion of Th1 cytokines, gamma interferon (IFN- $\gamma$ ), and IL-2. IL-12 plays an important role in the generation of Th1 responses to human pathogens $[23,24]$. Although the induction of IL-12 by intracellular organisms is necessary for a protective host Th1 response, the overexpression of Th1 cytokines and IL-12 may contribute to the development and perpetuation of chronic inflammatory and autoimmune diseases. Thus, understanding the regulated expression of IL-12 in macrophages may provide insight into the pathogenesis of infectious and inflammatory diseases, and could reveal novel approaches to altering immune responses [39].

To date, the anti-inflammatory effects of extracts and/or compounds isolated from the starfish $P$. nodosus have not been reported. Therefore, we assayed the anti-inflammatory activity of a methanolic extract, dichloromethane-soluble fraction, and water layer on pro-inflammatory cytokine (IL-12 p40, IL-6, and TNF- $\alpha$ ) production in LPSstimulated BMDCs using ELISA (Table 1). BMDCs were incubated in 48-well plates and treated for $1 \mathrm{~h}$ with the isolated compounds prior to stimulation with LPS $(10.0 \mathrm{ng} / \mathrm{mL})$. Supernatants were harvested $18 \mathrm{~h}$ after stimulation. Upon LPS treatment, dendritic cells (DCs) are known to secrete pro-inflammatory cytokines, including IL-12p40, IL-6, and TNF- $\alpha$.
Table 1 Anti-inflammatory effects of the extract/fractions on LPS-stimulated BMDCs

\begin{tabular}{llll}
\hline Extract/fractions & \multicolumn{3}{l}{$\mathbf{I C}_{\mathbf{5 0}}$ values $(\boldsymbol{\mu \mathbf { g }} / \mathbf{m L})^{\mathbf{a}}$} \\
\cline { 2 - 4 } & $\mathbf{I L - 1 2} \mathbf{p 4 0}$ & $\mathbf{I L}-\mathbf{6}$ & TNF-a \\
\hline $\mathrm{CH}_{2} \mathrm{Cl}_{2}$ fraction & $0.60 \pm 0.01$ & $3.29 \pm 0.09$ & $10.29 \pm 0.34$ \\
Water layer & $4.03 \pm 0.10$ & $80.76 \pm 1.96$ & $>100$ \\
MeOH extract & $2.48 \pm 0.08$ & $8.57 \pm 0.21$ & $26.19 \pm 0.64$ \\
SB203580 & $2.52 \pm 0.12$ & $1.67 \pm 0.13$ & $3.65 \pm 0.12$ \\
\hline
\end{tabular}

${ }^{a}$ The inhibitory effects are represented as giving $50 \%$ inhibition $\left(\mathrm{IC}_{50}\right)$ relative to the vehicle control. These data represent the average values of three repeated experiments (mean $\pm S D$ ). $I C_{50}$ values for selected extracts are given in column IL-12 p40, IL- 6 and TNF-a. Values $<100 \mu \mathrm{g} / \mathrm{mL}$ are considered to be active.

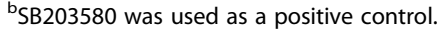

The methanolic extract significantly inhibited proinflammatory cytokine production, while the dichloromethane fraction and water layer showed more potent inhibitory effects (Figure 2). The methanolic extract of $P$. nodosus had inhibitory effects on IL-12 p40, IL-6, and TNF- $\alpha$ production $\left(\mathrm{IC}_{50 \mathrm{~S}}=2.48 \pm 0.08,8.57 \pm 0.21\right.$, and $26.19 \pm 0.64 \mu \mathrm{g} / \mathrm{mL}$, respectively). Since the methanolic extract significantly reduced inflammation, it was partitioned in dichloromethane/water to obtain a dichloromethanesoluble portion and an aqueous phase. As shown in Table 1, the dichloromethane-soluble fraction showed potent inhibitory activity towards LPS-stimulated IL-12 p 40 and IL-6 production $\left(\mathrm{IC}_{50 \mathrm{~s}}=0.60 \pm 0.01\right.$ and $3.29 \pm$ $0.09 \mu \mathrm{g} / \mathrm{mL}$, respectively), which was greater than in the presence of the methanolic extract $\left(\mathrm{IC}_{50 \mathrm{~s}}=2.48 \pm 0.08\right.$ and $8.57 \pm 0.21 \mu \mathrm{g} / \mathrm{mL}$ ). Moreover, the aqueous layer exerted potent suppressive effects on the production of IL-12 p40 $\left(\mathrm{IC}_{50}=4.03 \pm 0.10 \mu \mathrm{g} / \mathrm{mL}\right)$.

Subsequently, all of the isolated steroid derivatives (1-4) from the dichloromethane fraction and water layer of $P$. nodosus were tested for inhibitory effects on the production of the pro-inflammatory cytokines IL-12 p40, IL-6, and TNF- $\alpha$. The results obtained with 3-(4,5-dimethyl-2,5 thiazolyl)-2,5 diphenyl tetrazolium bromide (MTT) assays showed that steroid derivatives (1-4) did not exhibit significant cytotoxicity at concentrations up to $50.0 \mu \mathrm{M}$ at $24 \mathrm{~h}$ (data not shown). Of the tested compounds, 1-3 exerted greater inhibitory effects than SB203580 on IL-12 $\mathrm{p} 40$ production with $\mathrm{IC}_{50}$ values of $0.01 \pm 0.00,1.02 \pm 0.01$, and $3.11 \pm 0.08 \mu \mathrm{M}$, respectively, at the various concentration (Figure 3 and Table 2). This variability in inflammatory response inhibition by $\mathbf{1}-\mathbf{3}$ may be explained by the secretion of different levels of inflammatory factors upon LPS-stimulation.

Comparing the observed effects between the structurally steroid derivatives, (25S) $5 \alpha$-cholestane- $3 \beta, 6 \alpha, 8 \beta, 15 \alpha, 16 \beta$, 26 -hexol (1) is similar to that of (25S) $5 \alpha$-cholestane$3 \beta, 6 \alpha, 7 \alpha, 8 \beta, 15 \alpha, 16 \beta, 26-$-heptol (2) and (25S) $5 \alpha$-cholestane$3 \beta, 4 \beta, 6 \alpha, 7 \alpha, 8 \beta, 15 \alpha, 16 \beta, 26$-octol (3), except for the presence of hydroxy groups located at C-4 and/or C-7 in compounds 

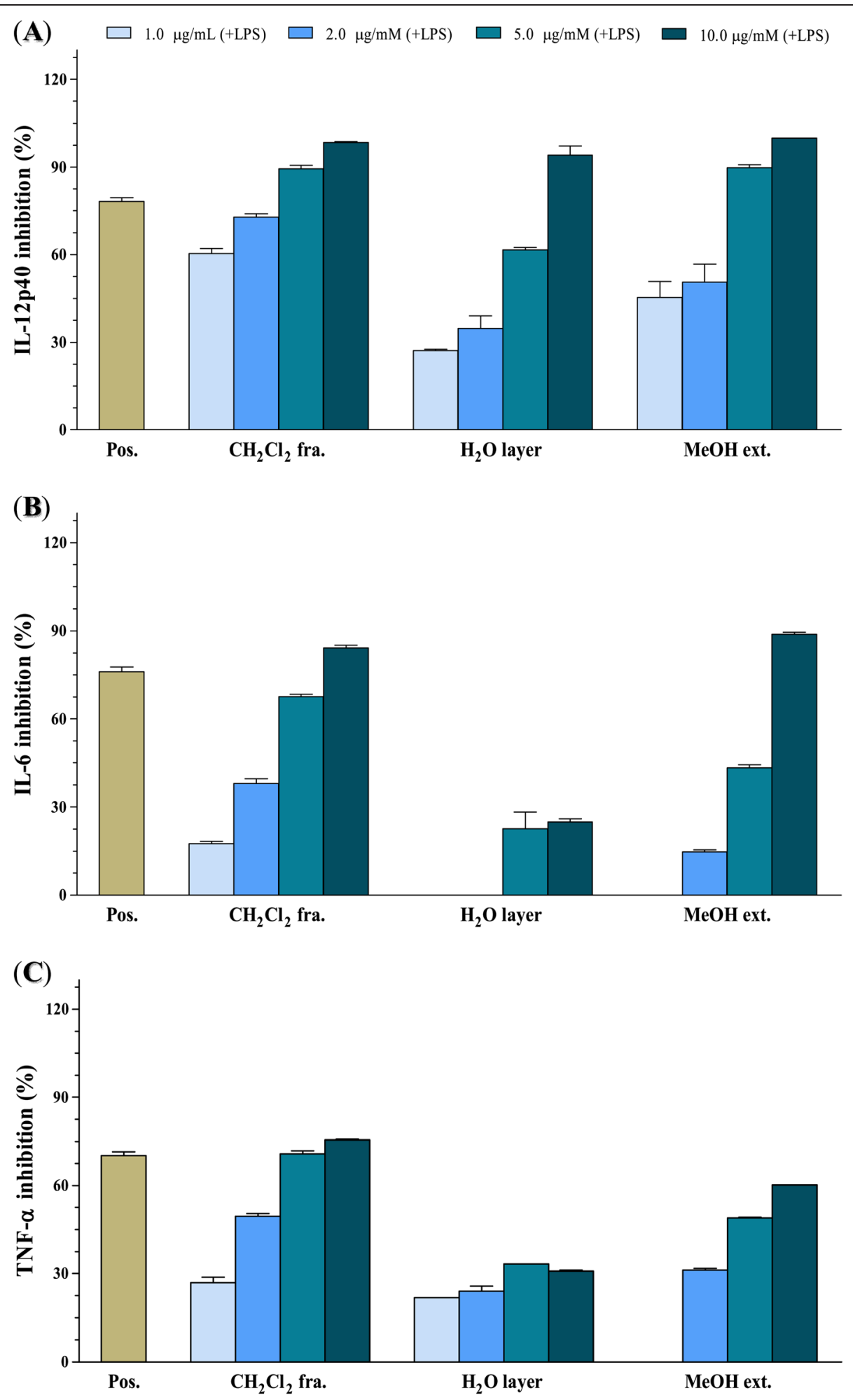

Figure 2 The effect of extract/fractions (1.0, 2.0, 5.0, and $10.0 \mu \mathrm{g} / \mathrm{mL}$ ) on IL-12 p40 (A), IL-6 (B), and TNF-a (C) production by LPS-stimulated BMDCs. The data were presented as inhibition rate (\%) compared to the value of vehicle-treated DCs. SB203580 was used as a positive control (Pos.).

2 and 3; these compounds had the greatest inhibitory activity towards LPS-stimulated IL-12 p40 production $\left(\mathrm{IC}_{50}=0.01 \pm 0.00 \mu \mathrm{M}\right)$, which was comparable to that of the positive control, SB203580 $\left(\mathrm{IC}_{50}=5.00 \pm 0.16 \mu \mathrm{M}\right)$. Previously, compounds 1-3 were isolated from Asterina pectinifera, Pentaceraster alveolatus, and Oreaster 


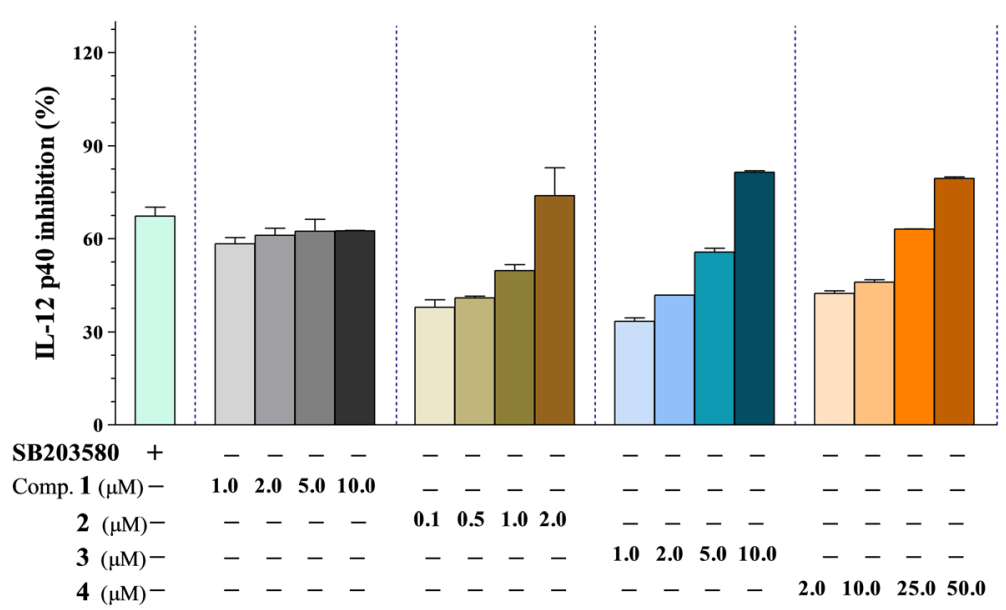

Figure 3 The effect of oxygenated derivatives of cholesterol 1-4 (0.1 to $50.0 \mu \mathrm{M})$ on IL-12 p40 production by LPS-stimulated BMDCs. The data were presented as inhibition rate (\%) compared to the value of vehicle-treated DCs. SB203580 was used as a positive control. Comp.: compound.

reticulatus [40-42], and they were evaluated for their antiviral activity against herpes simplex virus type 1 (HSV-1) and their cytotoxicity against human liver carcinoma (HepG2) cells in vitro [40]. Nodososide (4) is a polyhydroxylated steroid glycoside. Structurally, these glycosides are oxygenated derivatives of cholesterol that are glycosylated with a disaccharide chain, but 4 exhibited a moderate effect $\left(\mathrm{IC}_{50}=12.47 \pm 0.38 \mu \mathrm{M}\right)$ up to $50.0 \mu \mathrm{M}$, relative to the vehicle group. Our finding that steroid derivatives (1-3) possess significant antiinflammatory activity suggests that these related steroids might be interesting for further investigations for potential inflammatory diseases.

IL-6 is a pro-inflammatory cytokine that induces inflammatory upon secretion by $\mathrm{T}$ cells and macrophages in response to trauma, especially burns or other types of tissue damage [43]. It also strongly activates the immune system and enhances inflammatory responses, although based on some of its effects, it may also be classified as anti-inflammatory cytokine. Regarding IL-6, the methanolic extract and dichloromethane-soluble fraction showed inhibitory ciliary neurotropic factor activity toward LPS- stimulated IL-6 production $\left(\mathrm{IC}_{50 \mathrm{~s}}=8.57 \pm 0.21\right.$ and $3.29 \pm$ $0.09 \mu \mathrm{g} / \mathrm{mL}$, respectively). (25S) $5 \alpha$-cholestane-3 $3,4 \beta, 6 \alpha$, $7 \alpha, 8 \beta, 15 \alpha, 16 \beta, 26$-octol (3) inhibited IL-6 production significantly in LPS-stimulated BMDCs, with an $\mathrm{IC}_{50}$ value of $1.35 \pm 0.03 \mu \mathrm{M}$ (Table 2). The inhibitory effects of nodososide (4) included moderate inhibition of IL-6 production, with an $\mathrm{IC}_{50}$ value of $23.18 \pm 0.46 \mu \mathrm{M}$ (Figure 4). The remaining compounds did not show significant activity $\left(\mathrm{IC}_{50}>100 \mu \mathrm{M}\right)$ against IL-6 production.

Overexpression of the pro-inflammatory cytokines TNF- $\alpha$ and IL- 6 is associated with the development of autoimmune, inflammatory, and immunopathological diseases. Therefore, blocking TNF- $\alpha$, IL- 6 , and their respective signaling pathways may be effective for the treatment of inflammatory diseases. According to our results, the methanolic extract and dichloromethane-soluble fraction showed inhibitory effects on LPS-stimulated TNF- $\alpha$ production $\left(\mathrm{IC}_{50 \mathrm{~s}}=26.19 \pm 0.64\right.$ and $10.29 \pm 0.34 \mu \mathrm{g} / \mathrm{mL}$, respectively). Notably, not all of the isolated steroid derivatives (1-4) had significant inhibitory effects on TNF- $\alpha$ production $\left(\mathrm{IC}_{50}>100 \mu \mathrm{M}\right.$, Table 1 and 2). However, it is interesting to note that the methanolic extract extract and

Table 2 Anti-inflammatory effects of compounds (1-4) on LPS-stimulated BMDCs

\begin{tabular}{|c|c|c|c|}
\hline \multirow[t]{2}{*}{ Compounds } & \multicolumn{3}{|c|}{$I C_{50}$ values $(\mu \mathrm{M})^{\mathrm{a}}$} \\
\hline & IL-12 p40 & IL-6 & TNF-a \\
\hline (25S) 5a-Cholestane-3 $\beta, 6 a, 8 \beta, 15 a, 16 \beta, 26-$ hexol (1) & $0.01 \pm 0.00$ & $>100$ & $>100$ \\
\hline (25S) 5a-Cholestane-3 $\beta, 6 a, 7 a, 8 \beta, 15 a, 16 \beta, 26$-heptol (2) & $1.02 \pm 0.01$ & $>100$ & $>100$ \\
\hline 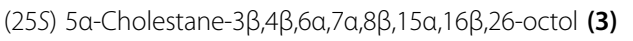 & $3.11 \pm 0.08$ & $1.35 \pm 0.03$ & $>100$ \\
\hline Nodososide (4) & $12.47 \pm 0.38$ & $23.18 \pm 0.46$ & $>100$ \\
\hline SB203580 & $5.00 \pm 0.16$ & $3.50 \pm 0.12$ & $7.20 \pm 0.13$ \\
\hline
\end{tabular}

${ }^{a}$ The inhibitory effects are represented as giving $50 \%$ inhibition $\left(\mathrm{IC}_{50}\right)$ relative to the vehicle control. These data represent the average values of three repeated experiments (mean \pm SD). IC 50 values for selected extracts are given in column IL-12 p40, IL-6 and TNF-a. Values $<100 \mu M$ are considered to be active. ${ }^{\mathrm{b}} \mathrm{SB} 203580$ was used as a positive control. 


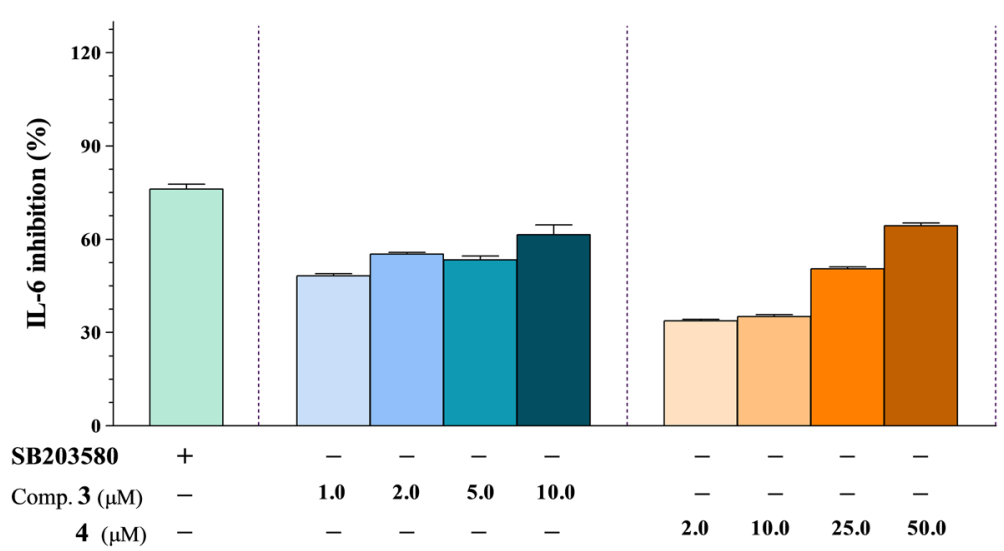

Figure 4 The effect of oxygenated derivatives of cholesterol 3 and $4(1.0$ to $50.0 \mu \mathrm{M})$ on IL-6 production by LPS-stimulated BMDCs.

The data were presented as inhibition rate (\%) compared to the value of vehicle-treated DCs. SB203580 was used as a positive control.

Comp.: compound.

dichloromethane-soluble fraction of $P$. nodosus were more active than the isolated steroid derivatives (1-4), suggesting the presence of other active derivatives, which could act individually or by synergy with the isolated steroid derivatives (1-4).

\section{Conclusion}

In conclusion, the methanolic extract and dichloromethane fraction showed potent inhibitory effects on the production of all three pro-inflammatory cytokines, with $\mathrm{IC}_{50}$ values ranging from $0.60 \pm 0.01$ to $26.19 \pm 0.64 \mu \mathrm{g} / \mathrm{mL}$. Potent inhibitory activities were observed for $(25 S) 5 \alpha$ cholestane- $3 \beta, 4 \beta, 6 \alpha, 7 \alpha, 8 \beta, 15 \alpha, 16 \beta, 26$-octol (3) on the production of IL-12 p40 and IL-6, and for (25S) $5 \alpha$ cholestane- $3 \beta, 6 \alpha, 8 \beta, 15 \alpha, 16 \beta, 26$-hexol (1) and (25S) $5 \alpha$ cholestane- $3 \beta, 6 \alpha, 7 \alpha, 8 \beta, 15 \alpha, 16 \beta, 26$-heptol (2) on the production of IL-12 p40. Moreover, nodososide (4) exerted moderate inhibitory effects on IL-12 p40 and IL-6 production. Additional studies are required to assess the mechanisms of action of these compounds and their potential use as novel anti-inflammatory agents. These results support the use of starfish steroid components to inhibit the secretion of pro-inflammatory cytokines, including IL-12 p40, IL- 6 , and TNF- $\alpha$, and to prevent and treat inflammatory diseases.

\section{Methods}

\section{General experimental procedures}

Optical rotations were determined on a JASCO P-2000 polarimeter. The UV spectrum was recorded on a JASCO V-630 spectrophotometer. IR spectra were obtained on a Bruker TENSOR 37 FT-IR spectrometer. The ${ }^{1} \mathrm{H}$ NMR $(500 \mathrm{MHz})$ and ${ }^{13} \mathrm{C}$ NMR $(125 \mathrm{MHz})$ spectra were recorded on a Bruker AM500 FT-NMR spectrometer and TMS was used as an internal standard. Column chromatography $(\mathrm{CC})$ was performed on silica gel (Kieselgel 60, 70-230 mesh and 230-400 mesh, Merck), porous polymer gel (Mitsubishi Chemical, Diaion HP-20, $70 \times 180 \mathrm{~mm}$ ), octadecyl silica (ODS, Cosmosil $140 \mathrm{C}_{18}$-OPN, Nacalai Tesque), and YMC RP-18 resins (30-50 $\mu \mathrm{m}$, Fuji Silysia Chemical). Thin layer chromatography (TLC) used pre-coated silica gel $60 \mathrm{~F}_{254}(1.05554 .0001$, Merck) and RP-18 $\mathrm{F}_{254 \mathrm{~S}}$ plates (1.15685.0001, Merck) and compounds were visualized by spraying with aqueous $10 \%$ $\mathrm{H}_{2} \mathrm{SO}_{4}$ and heating for $3-5$ minutes.

\section{Marine material}

The sample of the starfish $P$. nodosus was collected at Ha Long, Quangninh, Vietnam, in October 2012 and identified by Prof. Do Cong Thung (Institute of Marine Resources and Environment, VAST, Hanoi, Vietnam). A voucher specimen (PN-VHS-2012) was deposited at the Institute of Marine Resources and Environment and Institute of Marine Biochemistry, VAST, Vietnam.

\section{Extraction and isolation}

Fresh frozen samples of the starfish P. nodosus $(5.0 \mathrm{~kg}$ ) were ground and extracted three times with hot $\mathrm{MeOH}$ (at $50^{\circ} \mathrm{C}$ for $3 \mathrm{~h}$ each time). The obtained solutions were filtered, combined, and concentrated under reduced pressure to yield a dark viscous residue $(56.0 \mathrm{~g}, \mathrm{~A})$. This residue was suspended in water $(1.0 \mathrm{~L})$ and partitioned in turn with $\mathrm{CH}_{2} \mathrm{Cl}_{2}(3 \times 1.0 \mathrm{~L})$. The combined dichloromethane-soluble portions were evaporated under reduced pressure to afford $\mathrm{CH}_{2} \mathrm{Cl}_{2}$ fraction $(27.5 \mathrm{~g}, \mathrm{~B})$ and water layer $(C)$.

Extract B was crudely separated by silica gel (CC) using gradient concentrations of ethyl acetate (EtOAc) in $n$-hexane from 0 to $100 \%$ to yield four fractions (B-1 to B-4). Fraction B-4 (2.31 g) was further separated by silica gel $\mathrm{CC}$ using $\mathrm{CH}_{2} \mathrm{Cl}_{2}-\mathrm{MeOH}-\mathrm{H}_{2} \mathrm{O}$ (5:1:0.1) as eluents, to give three subfractions (B-1.1 to B-1.4). Subfraction 
B-1.3 (1.35 g) was then subjected to silica gel CC using eluent of $\mathrm{CH}_{2} \mathrm{Cl}_{2}-\mathrm{MeOH}$ (3.5:1), and further purified by reversed-phase flash CC (YMC Gel ODS-A, $60 \AA$, $400 / 500$ mesh) and eluting with $\mathrm{MeOH}-\mathrm{H}_{2} \mathrm{O}(2: 1)$ to

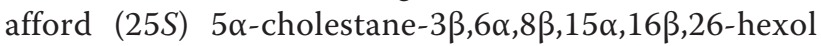
(1, $2.1 \mathrm{mg})$. Next, (25S) $5 \alpha$-Cholestane-3 $\beta, 6 \alpha, 7 \alpha, 8 \beta$, $15 \alpha, 16 \beta, 26$-heptol $(2,1.8 \mathrm{mg})$ was purified via the subfraction of B-1.2 $(0.21 \mathrm{~g})$ by silica gel $\mathrm{CC}$ and eluting with $\mathrm{CH}_{2} \mathrm{Cl}_{2}-\mathrm{MeOH}$ (4.5:1). Similarly, subfraction B-1.1 $(4.16 \mathrm{~g})$ was subjected to YMC RP-18 CC, using $\mathrm{MeOH}-$ acetone- $\mathrm{H}_{2} \mathrm{O} \quad(80: 10: 10)$ to yield (25S) $5 \alpha$-cholestane$3 \beta, 4 \beta, 6 \alpha, 7 \alpha, 8 \beta, 15 \alpha, 16 \beta, 26$-octol (3, $2.3 \mathrm{mg})$.

The water layer was desalted by Diaion ${ }^{\text {tw }}$ HP-20 CC and eluted first with water and then with $\mathrm{MeOH}$. The desalted water residue $(6.2 \mathrm{~g}, \mathrm{C})$ was separated by silica gel $\mathrm{CC}$ and eluted with $\mathrm{CH}_{2} \mathrm{Cl}_{2}-\mathrm{MeOH}$ (from 25:10:1, v/v/v) to yield five fractions ( $\mathrm{C}-1$ to $\mathrm{C}-5)$. Fraction $\mathrm{C}-3$ (1.2 g) was separated by silica gel $\mathrm{CC}$, using $\mathrm{CH}_{2} \mathrm{Cl}_{2}-\mathrm{MeOH}(5: 1)$ as the eluent to yield three subfractions (C-3.1 to C-3.3). Finally, subfraction C-3.3 (0.15 g) was further separated by Sephadex ${ }^{\circ} \mathrm{LH}-20 \mathrm{CC}$ using acetone-MeOH (1:2) as the mobile phase, followed by YMC RP-18 CC using $\mathrm{MeOH}-$ $\mathrm{H}_{2} \mathrm{O}$ (1:1) to afford nodososide $(\mathbf{4}, 3.5 \mathrm{mg})$.

\section{Marine product derivatives}

In total, $5.0 \mathrm{~kg}$ of finely chopped material were extracted with $\mathrm{MeOH}(5.0 \mathrm{~L})$ in glass jars with screw-on lids. The methanolic extracts were filtered, combined, and concentrated using a rotary vacuum evaporator at $40^{\circ} \mathrm{C}$ and then further dried in vacuo at ambient temperature for $24 \mathrm{~h}$. From the dichloromethane fraction and water layer of $P$. nodosus, four highly pure steroid derivatives (1-4) were isolated and their structures elucidated. Stock solutions of the tested compounds were prepared in dimethyl sulfoxide (DMSO), kept at $-20^{\circ} \mathrm{C}$, and diluted to the desired final concentration in fresh medium before each experiment. The final concentration of DMSO did not exceed $0.5 \%$ in any of the experiments to avoid effects cell growth.

\section{Cell viability assay}

The cell viability was determined by standard procedure of MTT assays (Sigma, St. Louis, MO, USA), which was based on the reduction of the dye MTT to formazan crystals, an insoluble intracellular blue product, by cellular dehydrogenases. Briefly, the cells at a concentration of $5 \times 10^{4}$ cells were seeded on a 96-well culture plate. After incubation for $1 \mathrm{~h}$ at $37^{\circ} \mathrm{C}$, cells were treated with extract, fractions, and compounds at various concentrations for $24 \mathrm{~h}$. Cells were added $0.2 \mathrm{mg}$ MTT (Sigma, St. Louis, MO) and then incubated at $37^{\circ} \mathrm{C}$ for $4 \mathrm{~h}$. The plate was centrifuged and the supernatants were aspirated. The formazan crystals in each well were dissolved in $250 \mu \mathrm{L}$ DMSO (Amresco, OH). The plates were agitated to ensure complete dissolution of the purple formazan crystals, and the optical density was measured at the wavelength $540 \mathrm{~nm}$ using an ELISA reader (Packard, Instrument Co., Downers Grove, IL).

\section{Cell cultures}

In this study, we used LPS-stimulated BMDCs as a model for testing the inhibitory effects of fractions and isolated compounds on the secretion of pro-inflammatory cytokines IL-12 p40, IL-6, and TNF- $\alpha$. BMDCs $\left(1 \times 10^{5}\right)$ were seeded in 48 -well plates at $37^{\circ} \mathrm{C}, 5 \% \mathrm{CO}_{2}$ for $1 \mathrm{~h}$, and then treated for $1 \mathrm{~h}$ with the compounds at concentrations of 0.1 to $50.0 \mu \mathrm{M}$, followed by stimulation with LPS (10.0 ng/mL, Figure 3). The supernatants were harvested $18 \mathrm{~h}$ after stimulation and IL-12 p40 secretion was measured using ELISA. SB203580, an inhibitor of cytokine suppressive binding protein/p38 kinase, was used as a positive control [44]. SB203580 inhibited IL-12 p40, IL-6, and TNF- $\alpha$ production with $\mathrm{IC}_{50}$ values of $5.00 \pm 0.16$, $3.50 \pm 0.12$, and $7.20 \pm 0.13 \mu \mathrm{M}$, respectively.

Bone marrow-derived dendritic cells were grown from wild-type C57BL/6 mice (Orient Bio Inc., Seoul, Korea) as previously described [45]. All animal procedures were approved by and performed according to the guidelines of the Institutional Animal Care and Use Committee of Jeju National University (\#2010-0028). Briefly, the mouse tibia and femur was obtained by flushing with Dulbecco's modified Eagle medium to yield bone marrow cells. The cells were cultured in Rosell Park Memorial Institute (RPMI) 1640 medium containing 10\% heat-inactivated fetal bovine serum (FBS; Gibco, Grand Island, NY, USA), $50.0 \mu \mathrm{M} \beta$-mercaptoethanol, and $2.0 \mathrm{mM}$ glutamine supplemented with $3 \% \mathrm{~J} 558 \mathrm{~L}$ hybridoma cell culture supernatant containing granulocyte-macrophage colonystimulating factor (GM-CSF). The culture medium was replaced with fresh medium every other day. At day six of culture, non-adherent cells and loosely adherent dendritic cell (DC) aggregates were harvested, washed, and resuspended in RPMI 1640 supplemented with 5\% FBS.

\section{Cytokine production measurements}

The BMDCs were incubated in 48-well plates in $0.5 \mathrm{~mL}$ containing $1 \times 10^{5}$ cells per well, and then treated with the isolated compounds (1-4) at different concentrations for $1 \mathrm{~h}$ before stimulation with $10.0 \mathrm{ng} / \mathrm{mL}$ LPS from Salmonella minnesota (Alexis, Famingdale, NY, USA). Supernatants were harvested $18 \mathrm{~h}$ after stimulation. Concentrations of murine IL-12 p40, IL-6, and TNF- $\alpha$, in the culture supernatant were determined by ELISA (BD PharMingen, San Diego, CA, USA) according to the manufacturer's instructions. The data are presented as means \pm S.D. of at least three independent experiments performed in triplicate. 
IL-12 p40 level in unstimulated DC: not detectable. IL-12 p40 level in LPS-stimulated DC: $51.34 \pm 0.66$ (ng/mL). IL-6 level in unstimulated DC: not detectable. IL-6 level in LPS-stimulated DC: $41.12 \pm 2.38(\mathrm{ng} / \mathrm{mL})$. TNF- $\alpha$ level in unstimulated DC: not detectable. TNF- $\alpha$ level in LPS-stimulated DC: $1.83 \pm 0.02(\mathrm{ng} / \mathrm{mL})$.

The inhibitory activity (I) was expressed as the inhibition rate (\%), which was calculated from the following formula:

$$
I=\frac{C_{\mathrm{dcv}}-C_{\mathrm{dcc}}}{C_{\mathrm{dcv}}} \times 100
$$

$C_{\mathrm{dcv}}$ : Cytokine level $(\mathrm{ng} / \mathrm{mL})$ in vehicle treated DC; $C_{\mathrm{dcc}}$ : Cytokine level $(\mathrm{ng} / \mathrm{mL})$ in compound treated DC.

\section{Statistical analysis}

The results are expressed as mean value \pm S.D. Statistical analysis was performed using one-way ANOVA. $P<0.05$ was considered statistically significant.

\section{Competing interests}

The authors declare that they have no competing interests.

\section{Authors' contributions}

NPT, BTTL, NXC, NHN, PVK, CVM, and YHK carried out conception and design of the study, acquisition of data, analysis and interpretation of data, drafting the manuscript and revising. JEK, SK, and YSK carried out acquisition of data, analysis and interpretation of data, statistical analysis. All authors read and approved the final manuscript.

\section{Acknowledgements}

This study was supported by Vietnam Academy of Science and Technology (code: VAST.TĐ.ĐAB.03/13-15), MOST and the Priority Research Center Program through the National Research Foundation of Korea (NRF) funded by the Ministry of Education, Science, and Technology (2009-0093815), Republic of Korea.

\section{Author details}

${ }^{1}$ Institute of Marine Biochemistry (IMBC), Vietnam Academy of Science and Technology (VAST), 18 Hoang Quoc Viet, Caugiay, Hanoi, Vietnam. ${ }^{2}$ College of Pharmacy, Chungnam National University, Daejeon 305-764, Republic of Korea. ${ }^{3}$ School of Medicine, Brain Korea 21 PLUS Program and Institute of Medical Science, Jeju National University, Jeju 690-756, Republic of Korea.

\section{Received: 16 October 2014 Accepted: 11 February 2015}

\section{Published online: 20 February 2015}

\section{References}

1. Lai PKK, Chan JYW, Wu SB, Cheng L, Ho GKW, Lau CP, et al. Antiinflammatory activities of an active fraction isolated from the root of Astragalus membranaceus in RAM 264.7 macrophages. Phytother Res. 2014;28:395-404.

2. Fahey TJ, Sadaty A, Jones WG, Barber A, Smoller B, Shires GT. Diabetes impairs the late inflammatory response to wound healing. J Surg Res. 1991;55:308-13.

3. Nathan C. Points of control in inflammation. Nature. 2002;420:846-52.

4. Giorgio T. Interleukin-12: A proinflammatory cytokine with immunoregulatory functions that bridge innate resistance and antigen-specific adaptive immunity. Annu Rev Immunol. 1995;13:251-76.

5. Kishimoto T. IL-6: from its discovery to clinical applications. Int Immunol. 2010:22:347-52.

6. Kishimoto T. The biology of interleukin-6. Blood. 1989;74:1-10.

7. Hirano T. Interleukin- 6 and its relation to inflammation and disease. Clin Immunol Immunopathol. 1992;62:S60-5.
8. Naka T, Narazaki M, Hirata M, Matsumoto T, Minamoto S, Aono A, et al. Structure and function of a new STAT-induced STAT inhibitor. Nature. 1997;387:924-9.

9. Feghali CA, Bost KL, Boulware DW, Levy LS. Mechanisms of pathogenesis in scleroderma. I. Overproduction of interleukin 6 by fibroblasts cultured from affected skin sites of patients with scleroderma. J Rheum. 1992;19:1207-11.

10. Bradley JR. TNF-mediated inflammatory disease. J Pathol. 2008;214:149-60.

11. Waage A, Halstensen A, Espevik T. Association between tumour necrosis factor in serum and fatal outcome in patients with meningococcal disease. Lancet. 1987;1:355-7.

12. Robak T, Gladalska A, Stepien $H$. The tumour necrosis factor family of receptors/ligands in the serum of patients with rheumatoid arthritis. Eur Cytokine Netw. 1998;9:145-54.

13. Dong G, Xu T, Yang B, Lin X, Zhou X, Yang X, et al. Chemical constituents and bioactivities of starfish. Chem Biodivers. 2011;8:740-91.

14. D'Orazio N, Gammone MA, Gemello E, Girolamo MD, Cusenza S, Riccioni G. Marine bioactives: Pharmacological properties and potential applications against inflammatory diseases. Mar Drugs. 2012;10:812-23.

15. Mayer AMS, Rodríguez AD, Berlinck RGS, Hamann MT. Marine pharmacology in 2005-6: Marine compounds with anthelmintic, antibacterial, anticoagulant, antifungal, anti-inflammatory, antimalarial, antiprotozoal, antituberculosis, and antiviral activities; affecting the cardiovascular, immune and nervous systems, and other miscellaneous mechanisms of action. Biochim Biophys Acta. 2009;1790:283-308.

16. Palyanova NV, Pankova TM, Starostina MV, Kicha AA, Ivanchina NV, Stonik VA. Neuritogenic and neuroprotective effects of polar steroids from the far east starfishes Patiria pectinifera and Distolasterias nipon. Mar Drugs. 2013;11:1440-55.

17. Suguna A, Bragadeeswaran S, Prabhu K, Priyatharsini S, Mohanraj M, Sivaramakrishnan S. Cytolytic and antinociceptive activities of starfish Protoreaster linckii (Blainvilli, 1893). J Pharm Pharmacol. 2013;7:2734-42.

18. Casapullo A, Finamore E, Minale L, Zoll F. Starfish saponins, part 49. New cytotoxic steroidal glycosides from the starfish Fromia monilis. J Nat Prod. 1993;56:105-15.

19. Zhou Q, Smith TL, Kummerow FA. Cytotoxicity of oxysterols on cultured smooth muscle cells from human umbilical arteries. Proc Soc Exp Biol Med. 1993;202:75-80.

20. Aiello A, Fattorusso E, Menna M, Carnuccio R, luvonet T. New cytotoxic steroids from the marine sponge Dysidea fragilis coming from the lagoon of Venice. Steroids. 1995;60:666-73.

21. Laille M, Gerald F, Debitus C. In vitro antiviral activity on dengue virus of marine natural products. CMLS, Cell Mol Life Sci. 1998;54:167-70.

22. Minme L, Piw C, Riccio R, Sorrentino C, Zoll F. Minor polyhydroxylated sterols from the starfish Protoreaster nodosus. J Nat Prod. 1984;47:790-5.

23. Riccio R, Zollo F, Finamore E, Minal L. Starfish saponins, 19. A novel steroidal glycoside sulfate from the starfishes Protoreaster nodosus and Pentaceraster alveolatus. J Nat Prod. 1985;48:266-72.

24. Pan K, Inagaki M, Ohno N, Tanaka C, Higuchi R, Miyamoto T. Identification of sixteen new galactocerebrosides from the starfish Protoreaster nodosus. Chem Pharm Bull. 2010;58:470-4.

25. Pan K, Tanaka C, Inagaki M, Higuchi R, Miyamoto T. Isolation and structure elucidation of GM4-type gangliosides from the okinawan starfish Protoreaster nodosus. Mar Drugs. 2012;10:2467-80.

26. Thao NP, Nam NH, Cuong NX, Quang TH, Tung PT, Tai BH, et al. Diterpenoids from the soft coral Sinularia maxima and their inhibitory effects on lipopolysaccharide-stimulated production of proinflammatory cytokines in bone marrow-derived dendritic cells. Chem Pharm Bull. 2012;60:1581-9.

27. Thao NP, Nam NH, Cuong NX, Quang TH, Tung PT, Dat LD, et al. Anti-inflammatory norditerpenoids from the soft coral Sinularia maxima. Bioorg Med Chem Lett. 2013;23:228-31.

28. Thao NP, Nam NH, Cuong NX, Tai BH, Quang TH, Ngan NTT, et al. Steroidal constituents from the soft coral Sinularia dissecta and their inhibitory effects on lipopolysaccharide-stimulated production of pro-inflammatory cytokines in bone marrow-derived dendritic cells. Bull Korean Chem Soc. 2013:34:949-52.

29. Thao NP, Dat LD, Ngoc NT, Tu VA, Hanh TTH, Huong PTT, et al. Pyrrole and furan oligoglycosides from the starfish Asterina batheri and their inhibitory effect on the production of pro-inflammatory cytokines in lipopolysaccharide-stimulated bone marrow-derived dendritic cells. Bioorg Med Chem Lett. 2013;23:1823-7. 
30. Thao NP, Cuong NX, Luyen BTT, Quang TH, Hanh TTH, Kim S, et al. Anti-inflammatory components of the starfish Astropecten polyacanthus. Mar Drugs. 2013;11:2917-26.

31. Thao NP, Cuong NX, Luyen BTT, Thanh NV, Nhiem NX, Koh YS, et al. Anti-inflammatory asterosaponins from the starfish Astropecten monacanthus. J Nat Prod. 2013;76:1764-70

32. Jeune MAL, Diaka JK, Brown J. Anticancer activities of pomegranate extracts and genistein in human breast cancer cells. J Med Food. 2005;8:469-75.

33. Wona HJ, Han CH, Kim YH, Kwon HJ, Kim BW, Choi JS, et al. Induction of apoptosis in human acute leukemia Jurkat T cells by Albizzia julibrissin extract is mediated via mitochondria-dependent caspase-3 activation. J Ethnopharmacol. 2006;106:383-9.

34. Lund E, Bjorkhem I. Selective decrease of the viability and the sterol content of proliferating versus quiescent glioma cells exposed to 25 -hydroxycholesterol. Acc Chem Res. 1995;28:241-9.

35. Smith LL, Johnson BH. Biological activities of oxysterols. Free Radicals Biol Med. 1989;7:285-332

36. Aupeix K, Weltin D, Mejia JE, Christ M, Marchal J, Freyssinet JM, et al. Oxysterol-induced apoptosis in human monocytic cell Lines. Immunobiology. 1995;194:415-28.

37. Efron PA, Tsujimoto H, Bahjat FR, Ungaro R, Debernardis J, Tannahill C, et al. Differential maturation of murine bone-marrow derived dendritic cells with lipopolysaccharide and tumor necrosis factor-alpha. J Endotoxin Res. 2005;11:145-60.

38. Kawai T, Akira S. The role of pattern-recognition receptors in innate immunity: update on Toll-like receptors. Nat Immunol. 2010;11:373-84.

39. Barrie AM, Plevy SE. The interleukin-12 family of cytokines: Therapeutic targets for inflammatory disease mediation. Clin Applied Immunol Rev. 2005;5:225-40

40. Peng $Y$, Zheng J, Huang R, Wang $Y, X u T$, Zhou $X$, et al. Polyhydroxy steroids and saponins from China sea starfish Asterina pectinifera and their biological activities. Chem Pharm Bull. 2010;58:856-8.

41. Zollo F, Finamore E, Minu L. Starfish saponins, 29. A novel steroidal glycoside from the starfish Pentaceraster alveolatus. J Nat Prod. 1986;49:919-21.

42. Ioriw M. Starfish saponins, part 53. A reinvestigation of the polar steroids from the starfish Oreaster reticulatus: Isolation of sixteen steroidal oligoglycosides and six polyhydroxysteroids. J Nat Prod. 1995;58:10-26.

43. Ding C, Cicuttini F, Li J, Jones G. Targeting IL-6 in the treatment of inflammatory and autoimmune diseases. Expert Opin Investig Drugs. 2009:18:1457-66.

44. Lee JC, Laydon JT, Mcdonnell PC, Gallagher TF, Kumar S, Green D, et al. A protein kinase involved in the regulation of inflammatory cytokine biosynthesis. Nature. 1994;372:739-46.

45. Koo JE, Hong HJ, Dearth A, Kobayashi KS, Koh YS. Intracellular invasion of orientia tsutsugamushi activates inflammasome in ASC-dependent manner PLOS ONE. 2012;7:e39042.

\section{Submit your next manuscript to BioMed Central and take full advantage of:}

- Convenient online submission

- Thorough peer review

- No space constraints or color figure charges

- Immediate publication on acceptance

- Inclusion in PubMed, CAS, Scopus and Google Scholar

- Research which is freely available for redistribution 